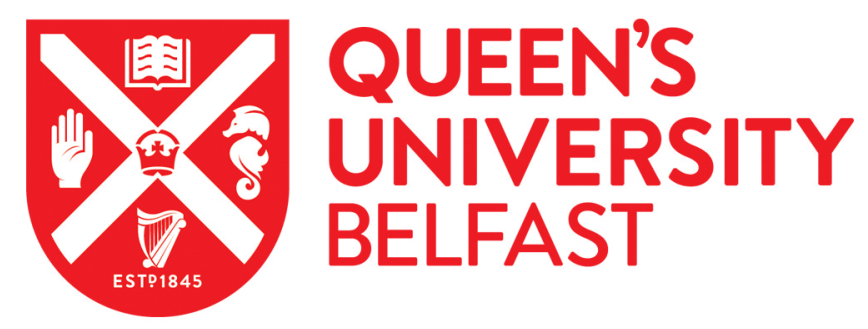

\title{
Factors influencing hospital costs of lung cancer patients in Northern Ireland
}

Fleming, I., Monaghan, P., Gavin, A., \& O'Neill, C. (2008). Factors influencing hospital costs of lung cancer patients in Northern Ireland. EurJ Health Econ, 9(1), 79-86. https://doi.org/10.1007/s10198-007-0047-4

\author{
Published in: \\ EurJ Health Econ
}

Queen's University Belfast - Research Portal:

Link to publication record in Queen's University Belfast Research Portal

\footnotetext{
General rights

Copyright for the publications made accessible via the Queen's University Belfast Research Portal is retained by the author(s) and / or other copyright owners and it is a condition of accessing these publications that users recognise and abide by the legal requirements associated with these rights.

Take down policy

The Research Portal is Queen's institutional repository that provides access to Queen's research output. Every effort has been made to ensure that content in the Research Portal does not infringe any person's rights, or applicable UK laws. If you discover content in the Research Portal that you believe breaches copyright or violates any law, please contact openaccess@qub.ac.uk.
} 


\title{
Factors influencing hospital costs of lung cancer patients in Northern Ireland
}

\author{
Ian Fleming • Pauline Monaghan · Anna Gavin • \\ Ciaran O’Neill
}

Received: 9 November 2006/Accepted: 22 February 20(07/Published online: 31 March 2007

(C) Springer-Verlag 2007

\begin{abstract}
Lung cancer is a major cause of morbidity and mortality. In this paper, the hospital costs incurred by 724 lung cancer patients diagnosed in 2001 were determined by review of case notes. These represented all patients diagnosed with lung cancer in Northern Ireland on whom data existed in that year. Total hospital costs in the 12 months from presentation for the 724 patients were $£ 3.99$ million. Average patient costs were $£ 5,956$ for patients diagnosed with non-small cell lung cancer and $£ 5,876$ for those with small cell lung cancer. The main component of cost was inpatient stay, representing between 62 and $84 \%$ of costs depending on cell type. Multivariate analyses revealed significant differences in cost related to staging, co-morbidities, age, and deprivation. Total annual hospital costs were 13 times as high as the estimated enforcement cost of the smoke-free legislation in Northern Ireland.
\end{abstract}

Keywords Lung cancer $\cdot$ Costs $\cdot$ Stage $\cdot$ Deprivation

JEL Classification $\quad$ C2 $\cdot$ I1 8

I. Fleming

University of Ulster, Jordanstown Campus,

Shore Road, Newtownabbey, Co. Antrim BT37 0QB, UK

P. Monaghan · A. Gavin

Northern Ireland Cancer Registry,

Centre for Clinical and Population Sciences,

Queens University Belfast. Grosvenor Road,

Belfast, BT 12 6BJ, UK

C. O'Neill (网)

School of Medicine and Dentistry,

Queens University Belfast, Grosvenor Rd,

Belfast BT12 6BP, UK

e-mail: ciaran.oneill@qub.ac.uk

\section{Introduction}

In 2002-2003, the UK National Health Service spent an estimated $£ 2.2$ billion on the provision of cancer care, a figure that has risen in real terms by $52 \%$ in the last decade [1]. Lung cancer is the second most common cancer in the UK, accounting for $14.2 \%$ of all tumors and over one-fifth $(22 \%)$ of all cancer deaths [2]. Contributory factors include exposure to asbestos, air pollution, metal-ores, and radon gas [3, 4], although tobacco remains the single greatest contributory factor, responsible for an estimated $90 \%$ of lung cancer cases $[3,4]$.

Patients typically present symptomatically. Histological type and stage at presentation influence treatment. Surgical resection is usually only pursued for stages I and II nonsmall cell lung cancer (NSCLC), with radiotherapy and chemotherapy remaining the treatment options for advanced NSCLC (III and IV) and small-cell lung cancer (SCLC). Survival is poor with only $10 \%$ relative 5-year survival [5]. Presently, only early stage NSCLC is potentially curable with palliative treatments prescribed for laterstaged disease and SCLC. No national screening program for lung cancer currently exists, the efficacy of such a program being unproven [6-9].

Previous studies have examined the hospital costs associated with lung cancer treatment in a variety of settings [10-13]. The average hospital treatment costs of NSCLC have been estimated in the UK at $\mathfrak{£} 6,150$ and $£ 5,668$ for SCLC (figures in 1993 prices) [14] with $96 \%$ of costs incurred in the first year of treatment and between 76 and $86 \%$ of treatment costs being associated inpatient episodes. While this study provided a comprehensive breakdown of costs for the different cell types, the relationship between costs and stage at diagnosis was not examined. Similarly, potential relationships between costs 
and patient characteristics such as age, deprivation, and comorbidities remain unexamined. The aim of this study is to re-examine hospital cost estimates and explore relationships between costs, cancer staging at diagnosis, and paltient characteristics such as age, co-morbidity, deprivation, and distance to treatment center.

\section{Materials and methods}

All lung cancer patients registered with the Northern Ireland Cancer Registry (NICR) in 2001 were selected for the study.' A review of hospital notes was undertaken to document each patient's individual treatment pathway for the 12 months post presentation. These included information on demography (age, gender, etc.), co-morbidities, diagnostic tests, treatments, treatment providers, duration of inpatient stay, histological type, staging information and patient survival.

Patients were categorized based on cell type as either NSCLC or SCLC, where cell type was unrecorded patients were categorized as non-microscopically verified lung cancer (NMV). Patients were further classified based on cancer staging. NSCLC patients were classified as either having limited disease (stages I and II), advanced disease (stages IIIa and IIIb), or extensive disease (stage IV). SCLC and NMV patients were classified as having limited disease (stages I and II), with other stages classitied as extensive disease.

From the dataset it was possible to construct a comprehensive profile of each patient's investigative and care pathway. A vector of unit costs was constructed using a survey of local service providers. The British National Formulary [15] was used to cost chemotherapy regimens. Radiotherapy was costed on the basis of cost per fraction administered. Costs were applied to activity data and aggregated for each patient at various stages-diagnostic, treatment, total hospital costs-all being expressed in 2004 prices. No costs incurred outside of the hospital such as general practitioner or community-care costs were examined in the study.

A co-morbidity score was calculated for each patient with relative risk of death used to weight each co-morbidity for each patient. The sum of these relative risks comprised the co-morbidity score, taking into account the number and seriousness of co-morbid conditions experienced [16]. The postcode for each patient was extracted and used to locate them in an enumeration district to which census data could be attributed. Census data included the Nobel deprivation score [17] based on the 2001 Census. The postcode also

\footnotetext{
The NICR is a population-based registry providing comprehensive cancer information for the entire population of Northern Ireland.
}

allowed the calculation of the distance from each patient's residence to the hospitals of presentation, diagnosis, and oncology. This was calculated using the RAC Route Planner, which provided the distance in miles, via the shortest route, given the existing road network [18].

Between-group differences were examined using $t$-tests having first examined data for skewness. Variations in costs across patients with different characteristics were undertaken using multiple regression analysis. Separate functions were employed to investigate the relationship between patient characteristics and total hospital cost, diagnosis cost, and treatment cost, respectively. A variety of functional forms were fitted to the data to improve goodness of fit, the square root of cost as a function of independent variables providing the best fit for the model (results of other models not shown). The final model included cell type, disease stage, age at diagnosis, co-morbidity score, and the Nobel deprivation score for the area in which the individual resided as explanatory variables. A further regression analysis was used to determine patient characteristics that influenced the duration of inpatient stay. All data were analyzed using SPSS version 11.0.

\section{Results}

In 2001 , there were 884 lung cancer patients registered with the NICR. Of these, 724 were included in the study; eight were excluded as diagnosis was made post-mortem (no data on resource use being available) and a further 152 patients were excluded due to insufficient data to enable cost calculation. An examination of the patients excluded revealed that these were significantly older $(p<0.01)$ than those included in the analysis and had lower survival at 1 year $(p<0.05)$. Differences in survival were most marked at 1 week and 1 month, indicating those excluded were likely to be very ill and unlikely to have experienced substantial or protracted hospital care.

The gender, histological type, and stage at presentation of patients included in the study are detailed in Table 1. The mean age at diagnosis for the 724 patients was 69 years (standard deviation 10 ) and over two-thirds were male. There was no significant difference between the mean age at diagnosis of NSCLC (68 years) and SCLC patients ( 66 years) though NMV patients, with a mean age of 74 years, were significantly older $(p<0.01)$ than those with diagnosed cell types.

Almost one-third of patients had no recorded co-morbidities; $34 \%$ had one co-morbidity, $24 \%$ had two comorbidities and $12 \%$ had more than two co-morbidities. The most frequently recorded co-morbidities were cardiovascular disease $(34 \%)$, chronic obstructive pulmonary disease (COPD) (29\%) and hypertension (17\%). (Given the 
Table 1 Lung cancer study patients, cell type, extent of disease at diagnosis and gender

\begin{tabular}{lrrrrrr}
\hline & Male & \multicolumn{1}{c}{$\%$} & Female & $\%$ & Total & $\%$ \\
\hline NSCLC & 296 & 64 & 153 & 60 & 449 & 62 \\
SCLC & 75 & 16 & 47 & 18 & 122 & 17 \\
NMV & 95 & 20 & 58 & 22 & 153 & 21 \\
Total & 466 & 100 & 258 & 100 & 724 & 100 \\
NSCLC limited & 77 & 26 & 56 & 37 & 133 & 30 \\
Advanced & 68 & 23 & 31 & 20 & 99 & 22 \\
Extensive & 92 & 31 & 42 & 27 & 134 & 30 \\
Un-staged & 59 & 20 & 24 & 16 & 83 & 18 \\
Total & 296 & 100 & 153 & 100 & 449 & 100 \\
SCLC limited & 11 & 15 & 6 & 13 & 17 & 14 \\
Extensive & 44 & 59 & 23 & 49 & 67 & 55 \\
Un-staged & 20 & 27 & 18 & 38 & 38 & 31 \\
Total & 75 & 100 & 47 & 100 & 122 & 100 \\
NMV limited & 11 & 12 & 11 & 19 & 22 & 15 \\
Extensive & 53 & 56 & 21 & 36 & 74 & 48 \\
Un-staged & 31 & 33 & 26 & 45 & 57 & 37 \\
Total & 95 & 100 & 58 & 100 & 153 & 100 \\
\hline NSC & & & & 100
\end{tabular}

NSCLC non-small cell lung cancer, SCLC small cell lung cancer, NMV non-microscopically verified

role of tobacco in lung cancer, the prevalence of respiratory conditions among co-morbidities is perhaps unsurprising.) Under half $(44 \%)$ of patients were admitted to hospital via an outpatient referral, while $42 \%$ presented as an emergency.

Hospital activity

The data revealed that patients were exposed to 16 different diagnostic procedures. These and the associated unit costs are presented in Table 2 while Table 3 provides the unit costs for cytotoxic drugs. Surgical procedures (defined as a thoracotomy and/or excisions) were recorded for 93 patients ( $13 \%$ of total) and were performed predominantly on NSCLC patients. Of all the surgical procedures, $62 \%$ were carried out on limited NSCLC patients and $24 \%$ on advanced NSCLC patients. Only three patients with other cell types received surgical intervention. Radiotherapy was given to 302 patients, $48 \%$ of patients with NSCLC and $48 \%$ of those with SCLC received radiotherapy compared to $13 \%$ of those with NMV. Chemotherapy was administered to 122 patients, $48 \%$ of SCLC patients, $13 \%$ of NSCLC patients and $3 \%$ of NMV patients.

Of the SCLC patients, $71 \%$ with limited disease received chemotherapy compared $1039 \%$ with extensive disease and $53 \%$ of patients with un-staged disease. Inpatient stays were recorded for 591 patients, $89 \%$ of SCLC patients, $81 \%$ of NSCLC patients and $77 \%$ of NMV patients. The mean inpatient stay was 20 days; 23 days for
SCLC patients, 20 days for NSCLC patients and 18 days for NMV patients.

\section{Costs}

Hospital costs are shown in Table 4 by disease type and staging. The mean hospital cost per patient with NSCLC was $£ 5,956$ ( $S D £ 4,780$ ); this was not significantly different from that of SCLC (mean $£ 5,876, \mathrm{SD} £ 3,830$ ). The mean cost of NMV patients was significantly lower at $£ 3,922$ $(\mathrm{SD} £ 4,551)(p<0.01)$. Inpatient stay accounted for 62 , 72 , and $84 \%$, respectively, of the costs for NSCLC, SCLC, and NMV patients. Diagnostic procedures accounted for between 10 and $15 \%$ of the total costs across the different types of disease. Chemotherapy accounted for $5 \%$ of total cost for both NSCLC and SCLC but only $1.5 \%$ of cost for NMV. NMV also had a lower percentage of costs $(5 \%)$ associated with radiotherapy compared to the expenditure on NSCLC (10\%) and SCLC (9\%). Surgical costs accounted for $11 \%$ of NSCLC expenditure, compared to less than $1 \%$ on SCLC and NMV.

The mean overall hospital costs for patients with limited NSCLC at diagnosis was $£ 6,947$ in the first year of treatment compared to $£ 6,543$ and $£ 4,566$ for those diagnosed with advanced and extensive disease, respectively. The average cost in the first year of treatment of patients with extensive NSCLC at diagnosis was significantly less than patients with other stages of non-small cell disease at diagnosis $(p<0.01)$. Similarly, when looking at SCLC and NMV lung cancer it was found that those diagnosed with earlier stage diseases cost significantly more than those diagnosed with later stage diseases in the first year of treatment $(p<0.05)$.

No significant cost difference was found between patients who presented via emergency admission or outpatient referrals at the $p>0.05$ level (data not presented). Likewise, no differences in average costs were found based on gender $p>0.05$. The youngest $20 \%$ of patients (mean age 53 years) cost $£ 7,360$ on average compared to $£ 4,169$ for the oldest $20 \%$ of patients (mean age 82 years) (see Fig. 1). The multiple deprivation scores revealed that individuals living in the most deprived quintile of enumeration districts cost $£ 4,871$ compared to $£ 5,764$ for the least deprived quintile.

In the multivariate analysis, significant differences in cost related to age and deprivation were apparent when cell type, stage, and co-morbidities were controlled for (see Table 5). The analysis also showed that cell type and stage were significant determinants of cost and that higher comorbidity was associated with lower costs.

For patients who had an inpatient stay, length of stay wals associated with stage. Shorter stays were observed for advanced or extensive disease compared to patients with 


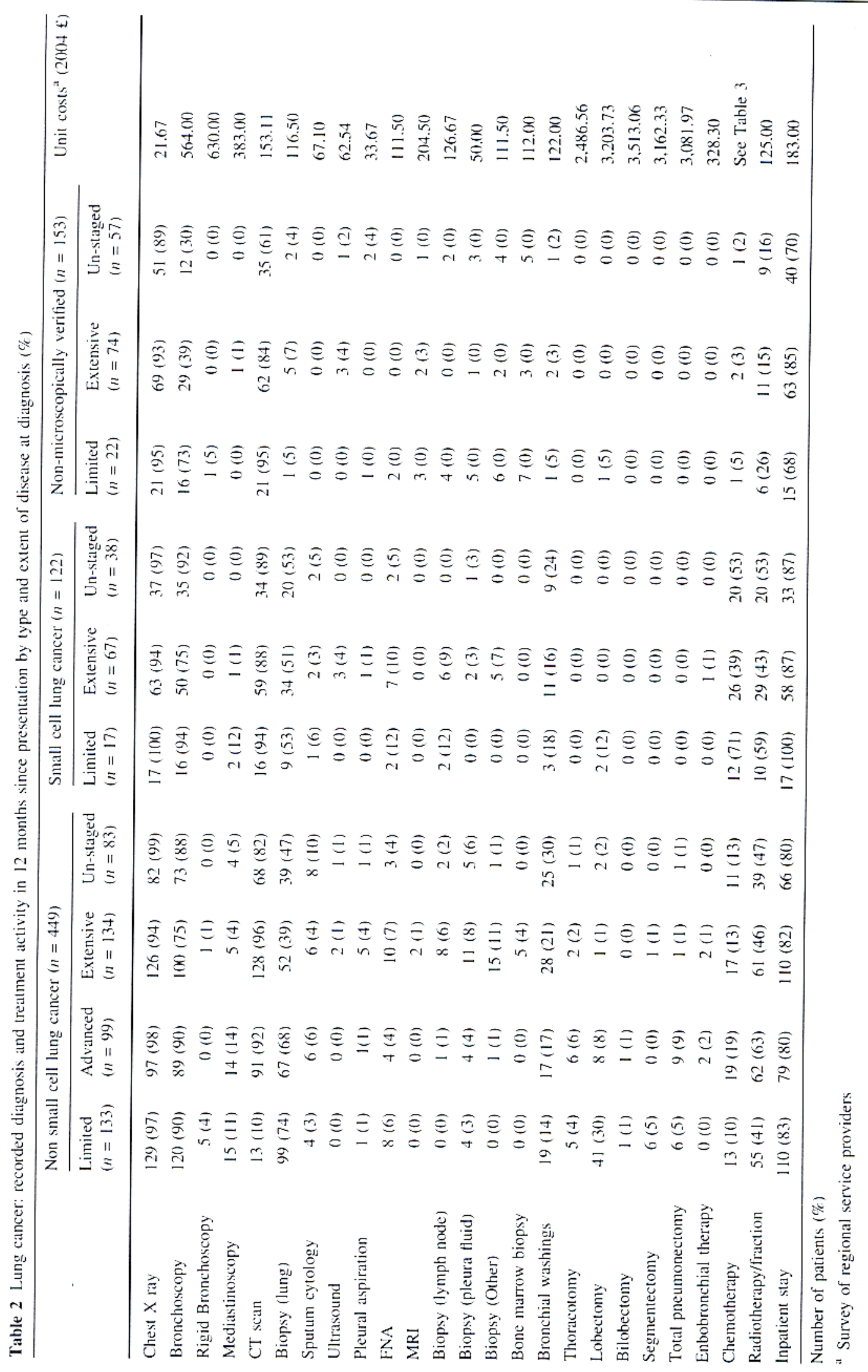


Table 3 Lung cancer: unit cost of chemotherapy agents lung cancer treatment (20)4 prices)

\begin{tabular}{lc}
\hline Chemotherapy agents" & Unit costs (2004 f) \\
\hline Taxol/ml & 22.4 \\
Carboplatin/ml & 0.38 \\
Cisplatin/ml & 0.50 \\
Etoposide/ml & 0.14 \\
Vincristine/ml & 8.83 \\
Cyclophosphamide/g & 5.04 \\
Vinblastine/ml & 1.31 \\
Doxorubicin/mg & 1.87 \\
Gemcitabine/mg & 0.16 \\
Mitomycin/mg & 1.85 \\
Methotrexate/ml & 0.22 \\
Temozolomide/mg & 0.60 \\
Vinorelbine/mg & 1.31 \\
Topotecan/mg & 78.13 \\
\hline
\end{tabular}

BNF-48, September 2004

limited disease. The greater the time between first presentation and diagnosis, the shorter was the inpatient stay $(p<0.05)$. The distance to the hospital of first presentation or hospital of diagnosis had no influence over duration of inpatient stay, however, the greater the distance from the cancer center to the patient's residence the longer the inpatient stay $(p<0.05)$ (see Table 6). (Earlier analyses had included age as an explanatory variable; as this proved insignificant it was removed.)

\section{Discussion}

The patients in this study represent $82 \%$ of those diagnosed with lung cancer in Northern Ireland in 2001. The $18 \%$ excluded had much shorter survival and the lack of data in their hospital records indicates minimal hospital intervention was provided. In effect, the study amounts to a population-based analysis of hospital costs associated with lung cancer.

The multivariate analyses revealed that (other variables controlled for) those with definite cell type cost significantly more than those with non-microscopically verified disease. While it is true that, collectively, NMVs were significantly older and presented at a later stage than those with defined cell types, these variables were controlled for in the analyses. This suggests other factors may lie behind the relatively lower expenditure on NMV patients. NMV patients may have poorer survival than those with other cell types, affording a shorter time period over which interventions may be attempted and thus costs incurred.

Table 4 Lung cancer: management and associated mean patient hospital cost for 12 months since presentation by cell type and extent of disease al diagnosis (2004 prices)

\begin{tabular}{|c|c|c|c|c|c|c|c|c|c|c|c|c|}
\hline & \multicolumn{2}{|c|}{ Diagnosis costs ( $\mathfrak{E}$ ) } & \multicolumn{2}{|c|}{ Surgical costs (£) } & \multicolumn{2}{|c|}{ Chemotherapy costs ( $f$ ) } & \multicolumn{2}{|c|}{ Radiotherapy costs (f犬) } & \multicolumn{2}{|c|}{ Inpatient costs ( $\mathfrak{E})$} & \multicolumn{2}{|c|}{ Total cost (f) } \\
\hline & No." & Mean' & No.: & Mean' & No." & Mean's & No." & Mean' & No.: & Mean ${ }^{\text {h }}$ & No." & Mean' \\
\hline \multicolumn{13}{|l|}{ NSCLC } \\
\hline Limited & 133 & 805.72 & 57 & 3.185 .28 & 13 & $1,864.05$ & 55 & $1,363.64$ & 110 & $4,872.79$ & 133 & $6,947.08$ \\
\hline Advanced & 99 & 814.73 & 23 & 3.121 .74 & 19 & $2,234.36$ & 62 & $1,435.48$ & 79 & $4,605,11$ & 99 & $6,542.57$ \\
\hline Extensive & 134 & 709.68 & 5 & $2,884.23$ & 17 & 2.609 .92 & 61 & 829.92 & 110 & $3,703.26$ & 134 & 4.566 .19 \\
\hline Un-staged & 83 & 751.49 & 4 & $2,994.00$ & 11 & 2.241 .82 & 39 & $1,227.56$ & 66 & $5,207.18$ & 83 & $5,910.35$ \\
\hline Overall & 449 & 769.02 & 89 & $3,143.35$ & 60 & $2,261.90$ & 217 & 1.209 .68 & 365 & $4,522.86$ & 449 & $5,955.69$ \\
\hline \multicolumn{13}{|l|}{ SCLC } \\
\hline Limited & 17 & 942.86 & 4 & 2.994 .00 & 12 & 650.84 & 10 & 1.387 .50 & 17 & $5,888.29$ & 17 & 8.483 .66 \\
\hline Extensive & 67 & 750.93 & 0 & - & 26 & 441.24 & 29 & $1,025.86$ & 58 & $4,464.57$ & 67 & $5,231.04$ \\
\hline Un-staged & 38 & 845.00 & 0 & - & 20 & 910.75 & 20 & $1,031.25$ & 33 & $4,580.55$ & 38 & $5,844.95$ \\
\hline Overall & 122 & 806.98 & 4 & 2.994 .00 & 58 & 646.51 & 59 & $1,088.98$ & 108 & $4,724.11$ & 122 & $5,875.49$ \\
\hline \multicolumn{13}{|l|}{ NMV } \\
\hline Limited & 22 & 616.22 & 1 & $3,203.73$ & 1 & $5,331.04$ & 6 & $1,875.00$ & 15 & $8,991.40$ & 22 & $7,646.03$ \\
\hline Extensive & 74 & 366.14 & 0 & - & 2 & 977.21 & 11 & $1,000.00$ & 63 & $3,735.52$ & 74 & $3,721,44$ \\
\hline Un-staged & 55 & 276.60 & 0 & - & 1 & $1,491.71$ & 9 & 694.44 & 40 & $3,339.75$ & 57 & $2,746.40$ \\
\hline Overall & 151 & 369.96 & 1 & 3.203 .73 & 4 & 2.194 .30 & 26 & $1,096.15$ & 68 & $4,269.48$ & 153 & 3.922 .50 \\
\hline Total patients & 722 & 691.97 & 92 & $3,145.32$ & 122 & 1.491 .71 & 302 & $1,179.33$ & 591 & $4,509.05$ & 724 & $5,512.51$ \\
\hline
\end{tabular}

NSCLC non-small cell lung cancer, SCLC small cell lung cancer. $N M V$ non-microscopically verified

* Number of patients in category

b Mean cost per patient in each category 


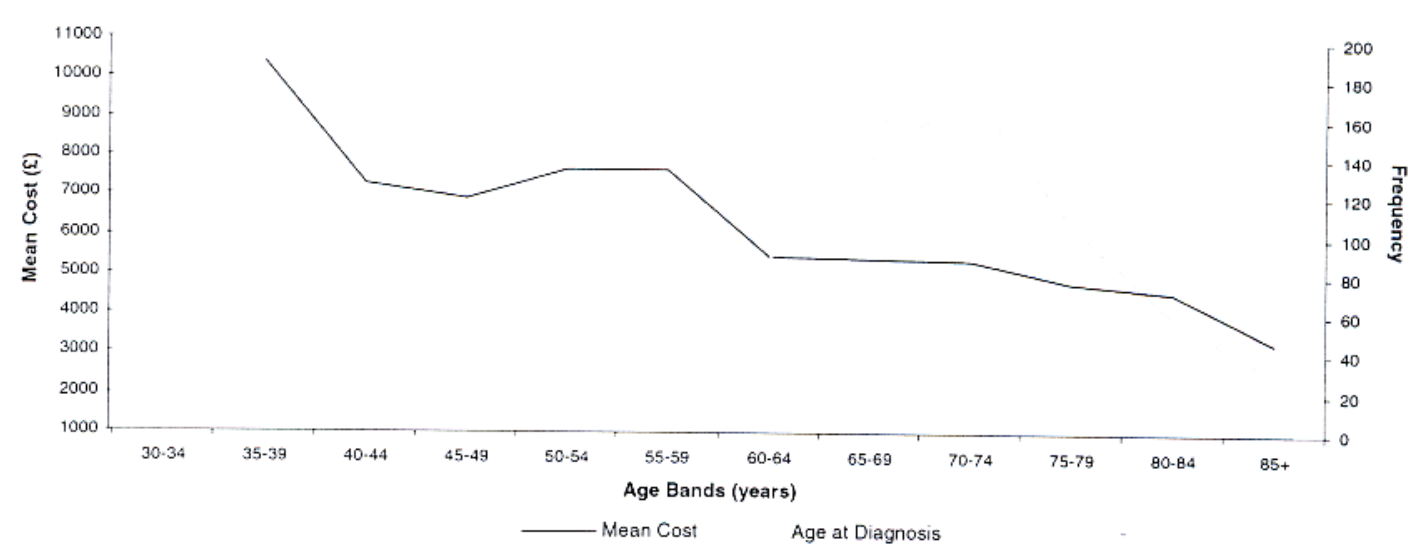

Fig. 1 Lung cancer: patient age at diagnosis and mean hospilal cost for 12 months since presentation (2004 prices)

Table 5 Regression analysis of overall hospital cost for 12 months since presentation (transformed)

\begin{tabular}{|c|c|c|c|c|c|c|c|c|c|}
\hline & \multicolumn{3}{|c|}{ Model a: Sqrt hospital cost } & \multicolumn{3}{|c|}{ Model b: Sqrt diagnosis cost } & \multicolumn{3}{|c|}{ Model c: Sqrt treatment costs } \\
\hline & B & $\mathrm{t}$ & $\mathrm{p}$ & B & 1 & $\mathrm{p}$ & B & 1 & $\mathrm{p}$ \\
\hline Constant & 114.939 & 13.279 & 0.000 & 32.033 & 16.669 & 0.000 & 113.814 & 11.593 & $0.0(0)$ \\
\hline NSCLC & 9.357 & 3.291 & 0.001 & 8.089 & 12.813 & 0.000 & 6.797 & 2.108 & 0.035 \\
\hline SCLC & 14.028 & 3.994 & 0.000 & 9.331 & 11.967 & 0.000 & 11.819 & 2.967 & 0.003 \\
\hline Extensive disease & -15.284 & -5.972 & 0.000 & -2.804 & -4.936 & 0.000 & -16.050 & -5.529 & 0.000 \\
\hline Un-staged disease & -10.673 & -3.712 & 0.000 & -2.320 & -3.635 & 0.000 & -10.683 & -3.276 & 0.001 \\
\hline Age at diagnosis & -6.30 & -5.863 & 0.000 & -0.158 & -6.604 & 0.000 & -0.683 & -5.605 & 0.000 \\
\hline Co-morbidity index & -3.245 & -1.981 & 0.048 & -0.794 & -2.184 & 0.029 & -3.574 & -1.924 & 0.055 \\
\hline \multirow[t]{2}{*}{ Economic deprivation score } & -0.102 & -2.017 & 0.044 & -0.0318 & -2.839 & 0.005 & -0.101 & -1.761 & 0.079 \\
\hline & \multicolumn{3}{|c|}{$\begin{array}{l}R^{2}=0.155, p=0.00, F=18.761 \\
\quad N=724\end{array}$} & \multicolumn{3}{|c|}{$\begin{array}{l}R^{2}=0.366, p=0.00, F=58.824 \\
\quad N=724\end{array}$} & \multicolumn{3}{|c|}{$\begin{array}{l}R^{2}=0.124, p=0.00, F=14.469, \\
\quad N=724\end{array}$} \\
\hline
\end{tabular}

Sqrt square root, $B$ beta (co-efficient of variation), $t$-statistic, $p p$-value

Table 6 Regression analysis of duration of inpatient stay in the 12 months since presentation

\begin{tabular}{|c|c|c|c|c|c|c|}
\hline & \multicolumn{3}{|c|}{ Model a: duration of inpatient stay (all patients) } & \multicolumn{3}{|c|}{ Model b: duration of inpatient stay (duration $>0$ days) } \\
\hline & B & 1 & $\mathrm{p}$ & $\mathrm{B}$ & 1 & $\mathrm{p}$ \\
\hline Constant & 23.154 & 12.710 & 0.000 & 28.858 & 14.918 & $0.00(0)$ \\
\hline Distance to cancer center & 0.0862 & 2.224 & 0.027 & 0.080 & 2.007 & 0.046 \\
\hline Advanced disease & -7.055 & -2.522 & 0.012 & -8.253 & -2.762 & 0.006 \\
\hline Extensive disease & -4.358 & -2.044 & 0.042 & -6.920 & -3.127 & 0.002 \\
\hline \multirow[t]{2}{*}{ Presentation to diagnosis (days) } & -0.0257 & -1.913 & $0.056^{\mathrm{a}}$ & -0.032 & -2.115 & 0.035 \\
\hline & \multicolumn{3}{|c|}{$R^{2}=0.035, p=0.004, F=3.957, N=724$} & \multicolumn{3}{|c|}{$R^{2}=0.052, p=0.001, F=5.059, N=591$} \\
\hline
\end{tabular}

$B$ beta (co-efficient of variation). $t$ t-statistic, $p /$-value

"Re-running this regression omitting presentation to diagnosis as an explanatory variable did not effect the inlerences drawn from the analysis. While it reduced the $F$ and $t$-values in the model they remained signilicant at $p<0.05$

Equally, these patients may have other complicating factors not well modeled in the co-morbidity measure used that may affect their suitability for treatment. Clearly, why NMVs cost less than those with defined cell type warrants closer investigation.
The stage at which the disease was diagnosed had a significant influence on diagnostic, treatment, and total hospital cost. In respect of all three disease types, costs were lower when presentation was later. This may in part reflect the shorter survival and lower tolerance to aggres- 
sive treatment among these patients as well as the more limited treatment options available to those with late-stage diagnoses. (A similar rationale would explain the relationship between co-morbidity, age and cost). That laterstage presentation is associated with lower hospital costs, is of course not to suggest that the earlier detection of cancers should be eschewed. It must be remembered that in examining costs we focus on one part of the cost-benefit equation only and then only for hospital costs. Evidence indicates that patients would have the best survival rate if the diagnosis of lung cancer is made while the lung nodule remains localized (i.e., early stage disease) suggesting the cost-benefit ratio may well favor earlier rather than later detection [19].

Delays between first presentation and diagnosis were associated with a shorter inpatient stay (Table 6). It is possible that the delay between presentation and diagnosis is related to unobserved variables such as patient attitudes towards treatment or the willingness to stay in the hospital-individuals who experience delays in diagnosis may, for example, be more reluctant to undergo hospital stays. Equally though, it could be that while stage at diagnosis is controlled for in the regression, this does not adequately reflect disease progression-small but aggressively growing nodules may be more difficult to detect but may imply poorer prognosis and with it shorter inpatient stay. Again, further investigation is warranted on this.

Regarding deprivation, care is warranted in the interpretation of its relationship with costs. It must be remembered that deprivation here is measured at an area level rather than on an individual basis. In as much as staging is controlled for, later presentation at diagnosis would not appear to explain why those from deprived areas should generate lower costs than those from more affluent areas. As with the relationship between delayed diagnosis and duration of inpatient stay, it could be that deprivation is correlated with other variables not included in the regression, for example, patient willingness to undergo particular procedures or again unobserved clinical characteristics perhaps related to long-term or continuing tobacco consumption, which is linked to deprivation $[20,21]$. Equally, it could be that uptake of some services outside the hospital environment, which substitutes for hospital care, is greater among those from deprived areas, the costs of which are not included in the study. That the degree of deprivation in the patient's area of residence is significant and negatively related to diagnostic, treatment and all hospital costs, however, remains. In a health care system where equity based on need is highly valued, the explanation for this variation warrants further investigation.

It should be noted that the unit costs on which our analyses are based are particular to Northern Ireland, though there is no reason to assume that they are atypical of those elsewhere in the UK and our estimates would not therefore be generalizable for it. In any event, the detail provided both on unit costs and activity would allow the interested reader to model costs for their own particular context.

\section{Conclusions}

This study has determined that the cost of hospital care for lung cancer in Northem Ireland for the first year amounts to approximately $£ 3.99 \mathrm{~m}$ ( $£ 5,510$ per case). It is interesting to note that this total represents 13 times the estimated enforcement cost of the Northern Ireland smoke-free legislation, which comes into effect on the 30th of April 2007 prohibiting smoking in enclosed places [22]. Consistent with intuition, the study has demonstrated a role for staging, co-morbidity, age, and cell type in determining costs. Given that these are related to the range of available treatments as well as tolerance to these this is perhaps unsurprising. That deprivation, delays in diagnoses, or an inability to diagnose a specific cell type play a role in service use when other variables are controlled for warrants investigation. That differences need not reflect differential access but rather differences in willingness to take up or tolerate treatment is possible. That those from deprived areas or with non-microscopically verified disease may be in some way disadvantaged in terms of access to services though is possible, and should be investigated.

It is clear that documenting the use and costs of services by individual patients, made possible by the information captured in cancer registries, can provide evidence of significant value to service planners. The low explanatory power of our models indicates that further work in this area could increase our understanding of cost variations. Expanding and using the data set routinely collected by such registries offers the potential to provide surveillance on and insights into these issues.

Acknowledgements The Northern lreland Cancer Registry (NICR) is funded by the Department of Health, Social Services and Public Safety Northern lreland (DHSSPSNI). Deirdre Fitzpatrick-Data management, Northern Ireland Cancer Registry Dr. Stranex-Belvior Park Hospital Belfast. Hospital Medical Records staff throughout Northern Ireland.

\section{References}

1. Yuen, P.: Compendium of Health Statistics. OHE, London (2005)

2. Cancer Research UK: CancerStats 2005, March, Cancer Research UK, London

3. Doll, R., Peto, R.: The Causes of Cancer, pp. 1220-1256. Oxford University Press, New York (1982)

4. Souhami, R., Tobias, J.: Cancer and its Management. Blackewell Science, Oxford, pp 179-197 (2003) 
5. Fitzpatrick, D., Gavin, A., Middleton, R.. Catney, D.: Cancer in Northern Ireland 1993-2001. A Comprehensive Report, Northern Ireland Cancer Registry (20(04)

6. Jett, J.R., Midthun. D.E.: Screening for lung cancer: current status and future directions: Thomas A. Neff lecture. Chest $\mathbf{1 2 5}(5$ Suppl), 158S-162S (20)(04)

7. Manser, R.: Screening for lung cancer: a review. Curr. Opin. Pulm. Med. 10, 266-271 (2004)

8. Ashton, R.W., Jetl, J.R.: Screening for non-small cell lung cancer. Semin. Oncol. 32, 253-258 (2005)

9. Rossi. A., Maione. P.. Colantuoni, G., Gaizo, F.D., Guerriero, C., Nicolella, D., Ferrara, C., Gridelli, C.: Screening for lung cancer: new horizons?' Crit. Rev. Oncol. Hematol. 56, 311-320 (2005)

10. Goodwin, P.J., Feld, R., Evans. W.K., Pater, J.: Cost-effectiveness of cancer chemotherapy: an economic evaluation of a randomized trial in small-cell lung cancer. J. Clin. Oncol. 6, 15371547 (1988)

11. Evans. W.K., Will, B.P., Berthelot, J.M., Wollson, M.C.: Estimatting the cost of lung cancer diagnosis and treatment in Canada: the POHEM Model. Can. J. Oncol. 5, 408-419 (1995)

12. Oliver, E., Killen, J., Kiebert, G., Hutton, J., Hall, R., Higgins, B., Bourke, S.. Paschen, B.: Treatment pathways, resource use and costs in the management of small cell lung cancer. Thorax 56 , $785-790(2001)$

13. Dedes, K.J., Szucs, T.D., Bodis, S., Joerger, M., Lowy, A., Russi, E.W.. Steinert. H.C., Weder, W., Stahel, R.A.: Management and costs of treating lung cancer patients in a university hospital. Pharmacoeconomics 22, 435-444 (2004)
14. Wolstenholme, J.L., Whynes, D.K.: The hospital costs of treating lung cancer in the United Kingdom. Br. J. Cancer 80, 215-218 (1999)

15. British Medical Association and Royal Pharmaceutical Society of Great Britain: Br. Natl Formul. 48, 384-410 (2004)

16. Charlson, M.E., Pompei, P., Ales, K.L., Mackenzie, C.R.: A new method of classifying prognostic comorbidit in longtidinal studies: development and validation. J. Chronic. Dis. 40, 373-383 (1987)

17. Nodel, M., Smith, G., Wright. G., Dibben, C., Lloyd, M., Shuttleworth, I.: Measures of Deprivation in Northern Ireland. Social Disadvantage Research Centre University of Oxford (2001)

18. RAC Route Planner, http://www.rp.ratc.co.uk/routeplanner (Accessed June 2004)

19. Deppermann, K.M.: Lung cancer screening-where we are in 2004 (take home messages). Lung Cancer 45(Suppl), S39-S42 (2004)

20. Jarvis, M.J.: A profile of tobacco smoking. Addiction 89, 1371$1376(1994)$

21. Wardle, J., Jarvis, M.J., Steggles, N., Sutton, S., Williamson, S., Farrimond, H., Cartwright, M., Simon, A.E.: Socioeconomic disparities in cancer-risk behaviors in adolescence: baseline results from the Health and Behaviour in Teenagers Study (HABITS). Prev. Med. 36, 72I-730 (20)(3)

22. Department of Health, Social Services and Public Safety Northern Ireland: The Smoking Order Consultation, pp. 64-72. DHSS \&PS, Northern Ireland (2006) 